\title{
Analytical and Experimental Study of Residual Stresses in CFRP
}

\author{
Chia-Chin Chiang, ${ }^{1}$ Vu Van Thuyet, ${ }^{1}$ Shih-Han Wang, ${ }^{2}$ and Liren Tsai ${ }^{1}$ \\ ${ }^{1}$ Department of Mechanical Engineering, National Kaohsiung University of Applied Sciences, 415 Chien-Kung Road, \\ Kaohsiung 807, Taiwan \\ ${ }^{2}$ Department of Chemical Engineering, I-Shou University, No. 1, Sec. 1, Syuecheng Rd., Kaohsiung 84001, Taiwan
}

Correspondence should be addressed to Liren Tsai; liren@cc.kuas.edu.tw

Received 15 September 2013; Accepted 7 November 2013

Academic Editor: Liang-Wen Ji

Copyright (c) 2013 Chia-Chin Chiang et al. This is an open access article distributed under the Creative Commons Attribution License, which permits unrestricted use, distribution, and reproduction in any medium, provided the original work is properly cited.

Fiber Bragg Grating sensors (FBGs) have been utilized in various engineering and photoelectric fields because of their good environment tolerance. In this research, residual stresses of carbon fiber reinforced polymer composites (CFRP) were studied using both experimental and analytical approach. The FBGs were embedded inside middle layers of CFRP to study the formation of residual stress during curing process. Finite element analysis was performed using ABAQUS software to simulate the CFRP curing process. Both experimental and simulation results showed that the residual stress appeared during cooling process and the residual stresses could be released when the CFRP was machined to a different shape.

\section{Introduction}

Carbon fiber composites have been widely considered as the optimal replacement material for various industrial products. For composite materials, the inherent defects could greatly hamper the reliability and durability of the resultant products. There have been many studies of embedded stress sensors, particularly for damage detection in composite materials [1, 2]. FBGs possess great compatibility with CFRP [3], and by embedding FBG inside carbon fiber composites, the residual strain of the carbon fiber composites during production could be easily monitored. Because of thermal expansion, coefficient of the elements in the composite materials is different, and the shape of the optical spectra changed during curing process. These changes induced a shift in wavelengths of the optical fiber sensors, which could be converted to residual stress [4]. In this research, residual stresses of carbon fiber reinforced polymer composites (CFRP) were studied using both experimental and analytical approach. The simulation of residual stress during cooling process was carried out using ABAQUS. Through comparison between experimental and simulation results, the formation of residual stress in the CFRP was confirmed.

\section{Materials and Methods}

2.1. Fiber Bragg Grating Sensors (FBG). The FBG involved was fabricated from single cladding photosensitive fiber using the side writing method. The photosensitive fiber was produced by Fibercore Co. Ltd. (PS1250/1550). The FBGs are photoimprinted in photosensitive optical fiber by $248 \mathrm{~nm}$ UV radiation from a KrF Excimer laser. The impulse frequency of laser is $10 \mathrm{~Hz}$. Along the fiber core, the FBG has periodic refractive index modulation with a period of $1.05 \sim 1.08 \mu \mathrm{m}$. This resulted in a peak Bragg reflecting wavelength of 1540 $1564 \mathrm{~nm}$. The reflectivity of the resulting FBG was about 99\% and the FWHM (Full width Half Maximum) of the FBG is about $0.175 \mathrm{~nm}$. Light sources export energy to the carbon fiber composite with FBG by coupler, and the energy change was then recorded and analyzed by oscilloscope. The residual strain of imbedded carbon fiber composites could be determined by comparing the wavelength difference in the FBG before and after curing process using

$$
\frac{\Delta \lambda}{\lambda}=\left(1-P_{e}\right) \varepsilon+(\alpha+\zeta) \Delta T,
$$




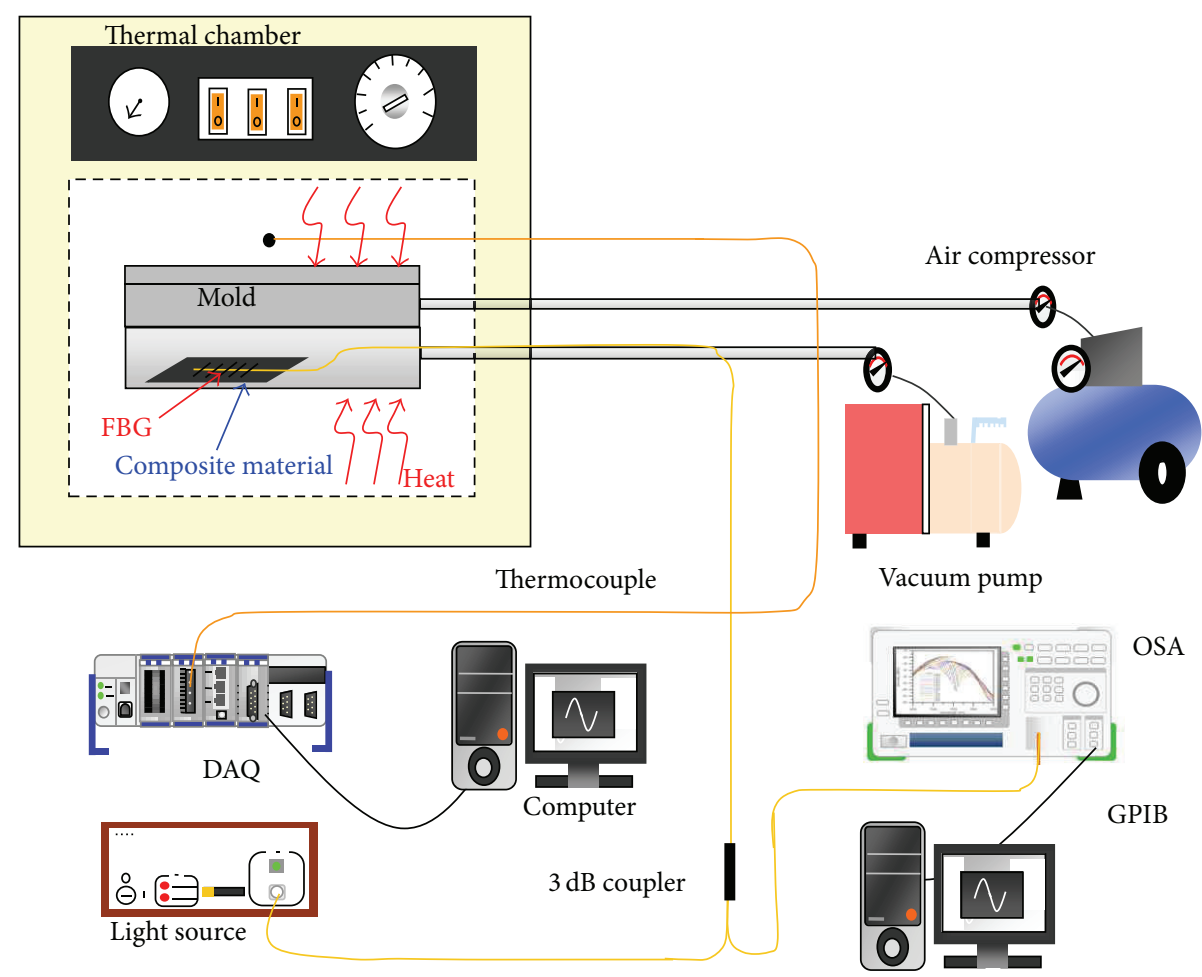

FIGURE 1: Experiment set-up for using FBG sensors to monitor the curing process of composite.

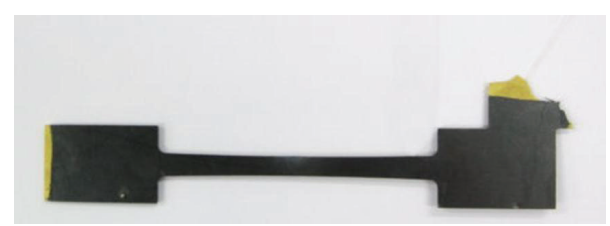

Figure 2: FBG embedded CFRP which has been machined to dogbone shape.

where $\lambda$ and $\Delta \lambda$ represent the original and variation wavelength of optical fiber, and $P_{e}$ indicates the light elastic constant. $\alpha$ and $\zeta$ represent the coefficient of thermal expansion and thermo-optic coefficient of the optical fiber, respectively. Figure 1 shows the experimental arrangement of the proposed FBG system for monitoring the curing process of composite.

\subsection{Specimen Assembly}

2.2.1. Materials and Specimen Preparation. Prepregs from Advanced International Multitech (batch number: B10037 K) were utilized to compose the epoxy carbon fiber specimens. A series of $0^{\circ}$ specimens was prepared: (1) fold the carbon laminate with ten plies (about 1 millimeter) by $0^{\circ}$; (2) put the Fiber Bragg Grating (FBG) on the center of laminate plane; (3) let the optical fiber get out from lateral direction, and then take another ten plie of $0^{\circ}$ prepreg laminate to cover the FBG, totally 20 carbon fiber plies.

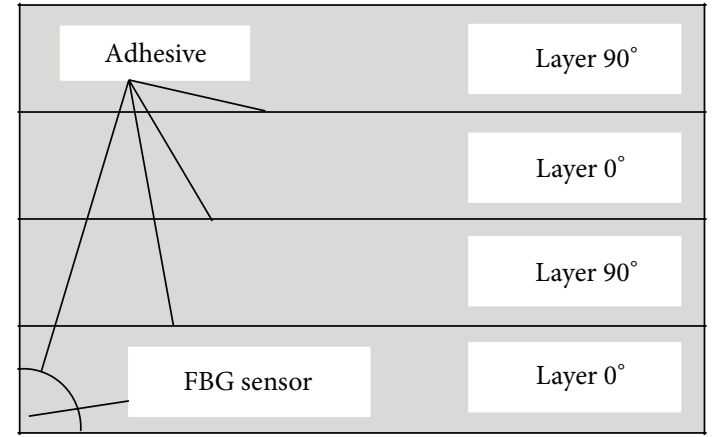

Figure 3: 2D finite element model.

2.2.2. Dog-Bone Shaped Specimens. After the specimens were cured properly, each assembly was then machined to dogbone shape for residual stress release experiments, as shown in Figure 2. A stainless steel fixer was designed to hold the carbon-fiber specimens. The fixer provides axial support during the experiments.

2.3. Finite Element Model. Finite element simulations were performed to determine the residual stress distribution during the curing process of the model, when its curing temperature is about $140^{\circ} \mathrm{C}$. The model is two dimensions (2D) created in ABAQUS software. In order to reduce the time for simulation, a quarter of the model is used to do simulation analysis. The model is shown in Figure 3. 


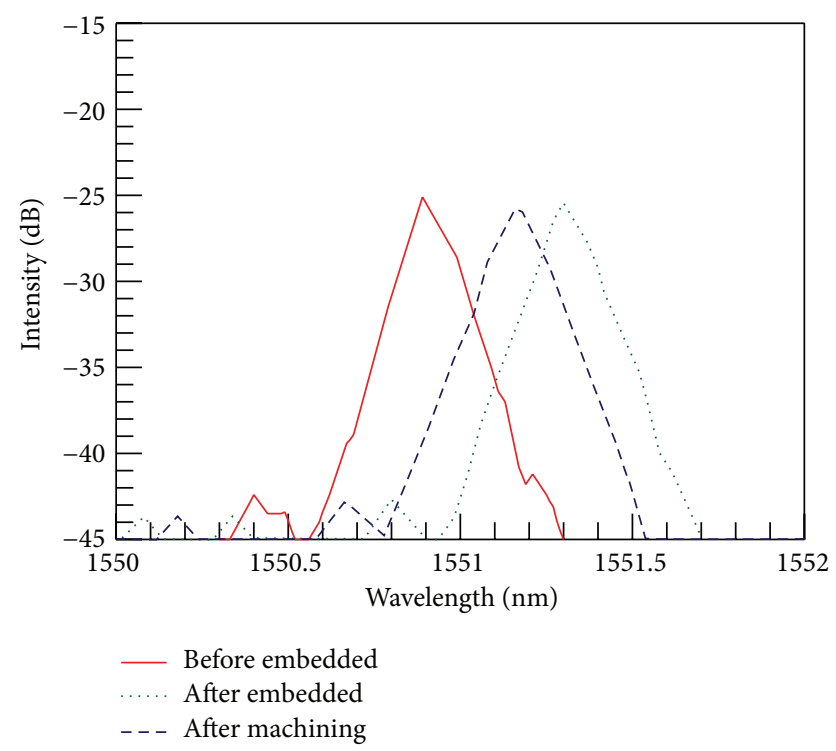

FIGURE 4: The FBG spectra of the specimen-1 at different stage of the process.

To calculate residual stresses in cooling process, sequential coupled thermal-stress analysis was constructed. The temperature-displacement options in ABAQUS was utilized for this simulation. The thermal residual stress and strain were interpolated from the temperature at the nodes of the model. The temperature varies with time and positions which resulted in internal stresses in the model.

The Fiber Bragg grating is embedded in CFRP. In curing process, the FBG was subjected to both the shrinkage effect of the epoxy and the fiber reinforcement. FBG is subjected to two directions that are $x$-axis and $y$-axis. The strain of FBG was changed by residual stress. This leads to the change in the form of the spectrum's optical during the curing process. So using ABAQUS can be simulated and found $\varepsilon_{x}\left(E_{11}\right), \varepsilon_{y}\left(E_{22}\right)$ and $\gamma_{x-y}\left(E_{12}\right)$ to calculate residual strain.

\section{Results and Discussion}

In the present study, several FBG embedded FRP specimens were examined. After the specimens are cooled down to atmosphere temperature, the wavelength of each specimen was recorded. Figure 4 showed the wavelength of specimen-1 before and after curing, and from the wavelength difference, the residual strain was determined to be $0.034 \%$. Figure 5 showed the wavelength of specimen-2 before and after curing, and from the wavelength difference, the residual strain was determined to be $0.011 \%$. The blue curves in both figures represent the measured FBG wavelength after specimens were machined to dog-bone shape, as shown in Figure 2. It is observed that after machining, the residual strain reduced at least $40 \%$.

Figures 6 and 7 showed the analytical simulation resulted obtained from finite element analysis calculations. In Figure 6, axial and shear strains at cross section of FRP during cooling process were shown. The difference between

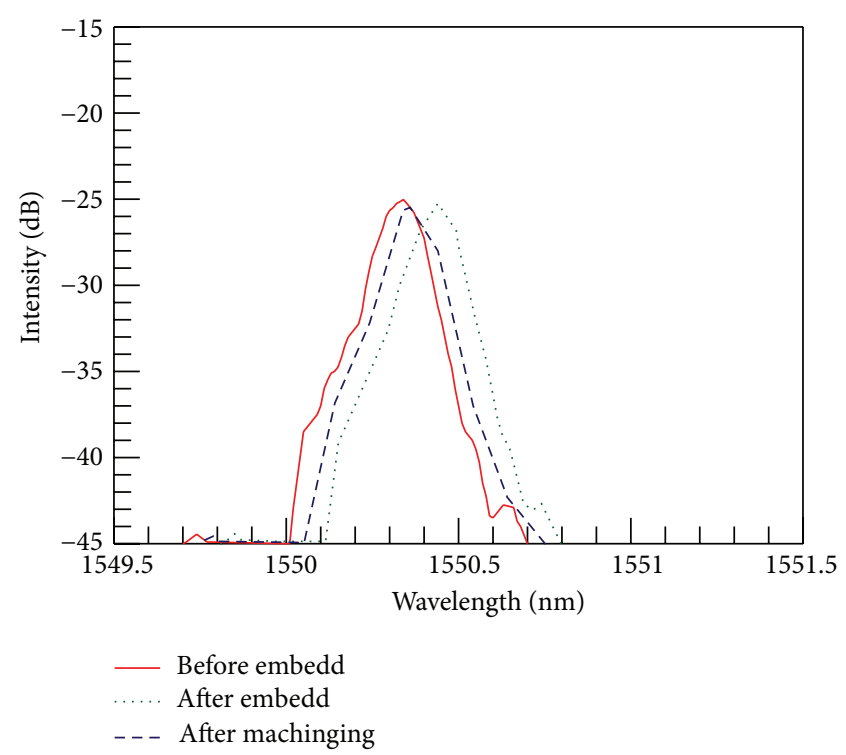

FIgURE 5: The FBG spectra of the specimen-2 at different stage of the process.

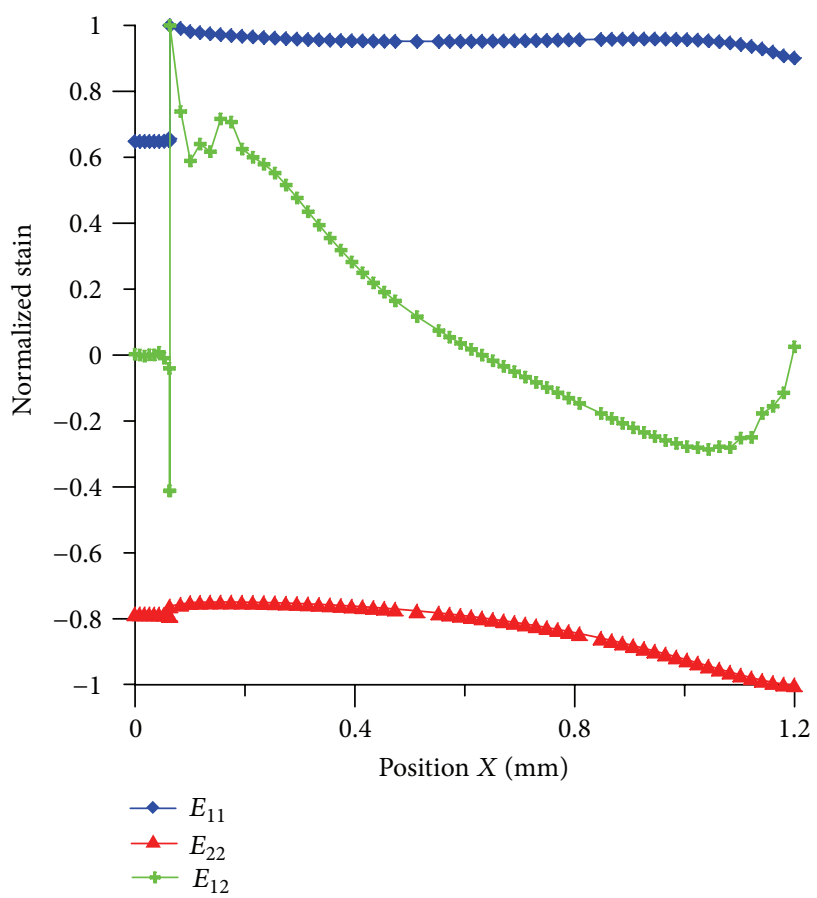

FIgURE 6: Axial and shear strains at the cross section of the FRP.

strains at the center and the strains at the boundary of FBG was quite clear. In Figure 7, the residual stress of FBG during curing process was studied, and compression residual stress was observed at steady state.

\section{Conclusion}

FBGs were embedded inside FRP specimens to study the relationship between residual stress and curing process. 


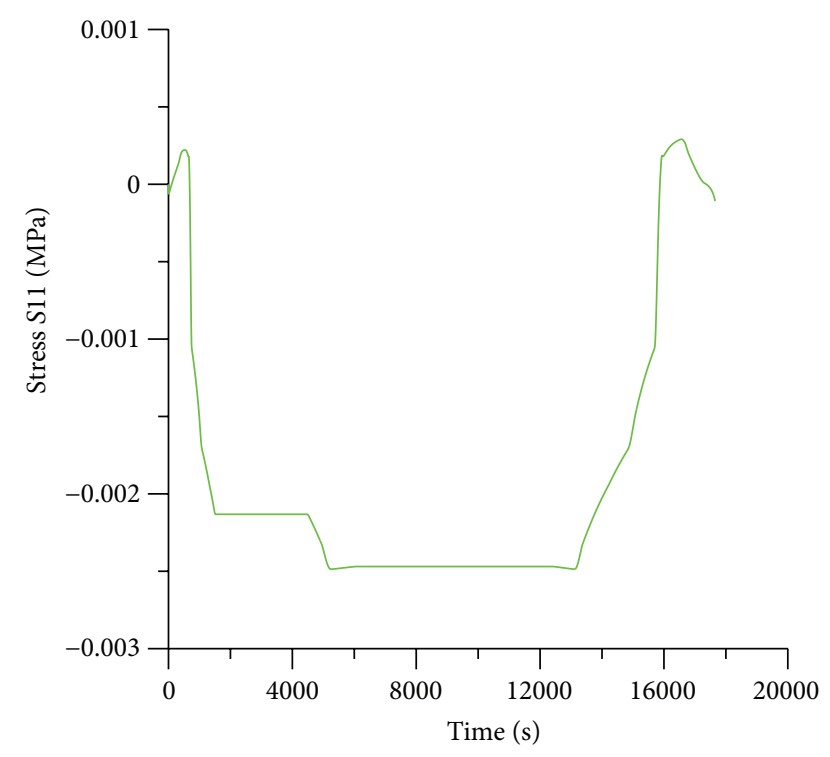

FIGURE 7: Stress S11 at core of FBG with cooling rate $1.92^{\circ} \mathrm{C} / \mathrm{min}$.

The residual strain was able to be monitored during curing and the residual strain was recorded for each of specimens. The residual stresses of FRP specimens were measured before and after machining. When the specimens were machined to dog-bone shape, clear residual stress drop was observed. The averaged reduction of residual stress after machining was about $40 \%$.

The simulation of FBG sensor during curing process was performed using coupled temperature and displacement. The influence of the cooling process on residual stress in carbon fiber reinforced polymer was evident. The thermal residual stress is strongly affected by the cooling rate. It is concluded that proper temperature control of the curing process can reduce considerable residual stress in CFRP.

\section{Acknowledgment}

This work is supported by the National Science Council, Taiwan (Grant no. NSC 101-2221-E-151-014).

\section{References}

[1] S. Ogihara, N. Takeda, and A. Kobayashi, "Experimental characterization of microscopic failure process under quasi-static tension in interleaved and toughness-improved CFRP cross-ply laminates," Composites Science and Technology, vol. 57, no. 3, pp. 267-275, 1997.

[2] Y. Okabe, S. Yashiro, R. Tsuji, T. Mizutani, and N. Takeda, "Effect of thermal residual stress on the reflection spectrum from fiber Bragg grating sensors embedded in CFRP laminates," Composites A, vol. 33, no. 7, pp. 991-999, 2002.

[3] L. Tsai, T. C. Cheng, C. L. Lin, and C. C. Chiang, "Application of the embedded optical fiber bragg grating sensors in curing monitoring of Gr/Epoxy laminated composites," in Smart Sensor Phenomena, Technology, Networks, and Systems 2009, vol. 7293 of Proceedings of SPIE, March 2009.
[4] L. Sorensen, T. Gmür, and J. Botsis, "Residual strain development in an AS4/PPS thermoplastic composite measured using fibre Bragg grating sensors," Composites A, vol. 37, no. 2, pp. 270281, 2006. 

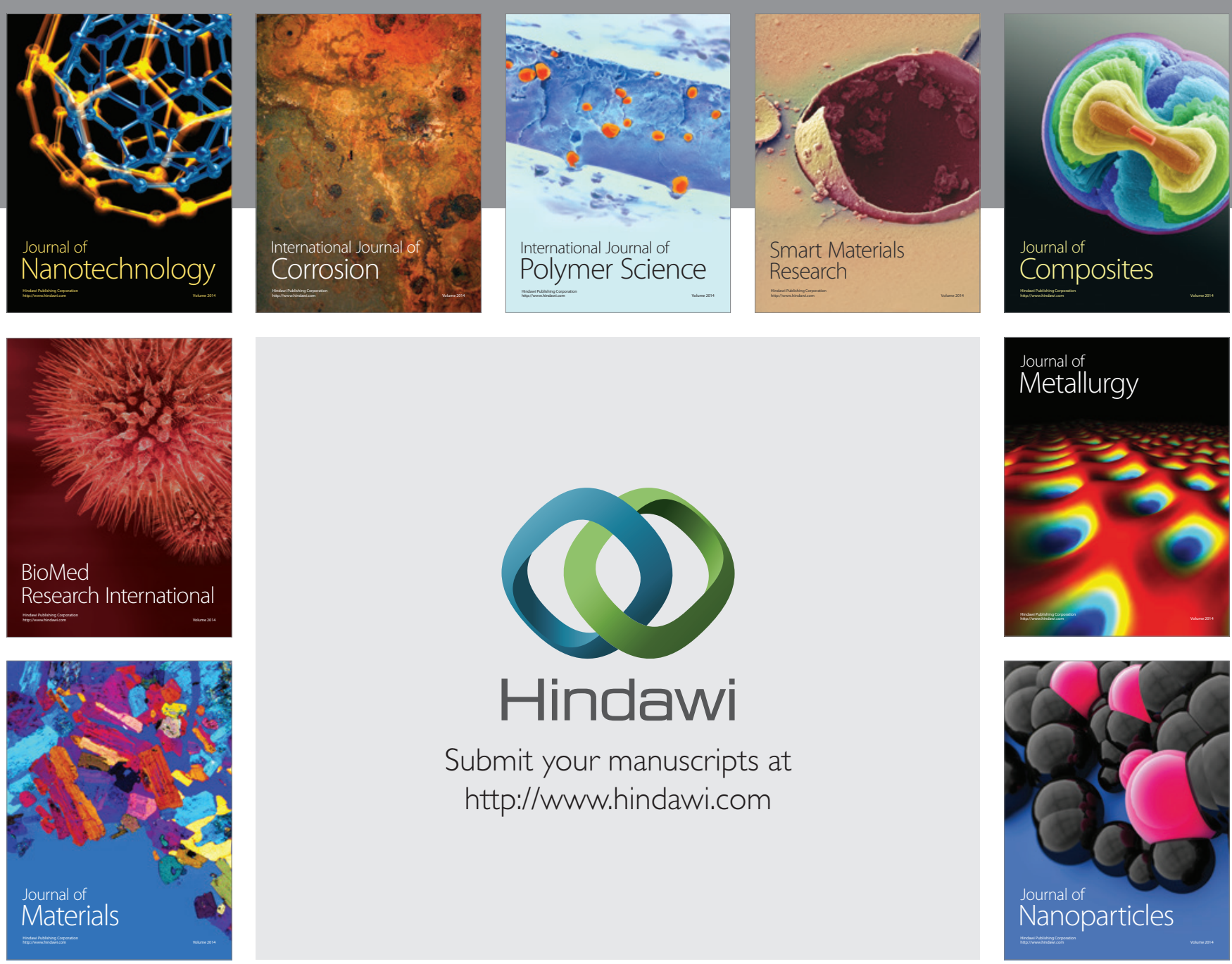

Submit your manuscripts at http://www.hindawi.com
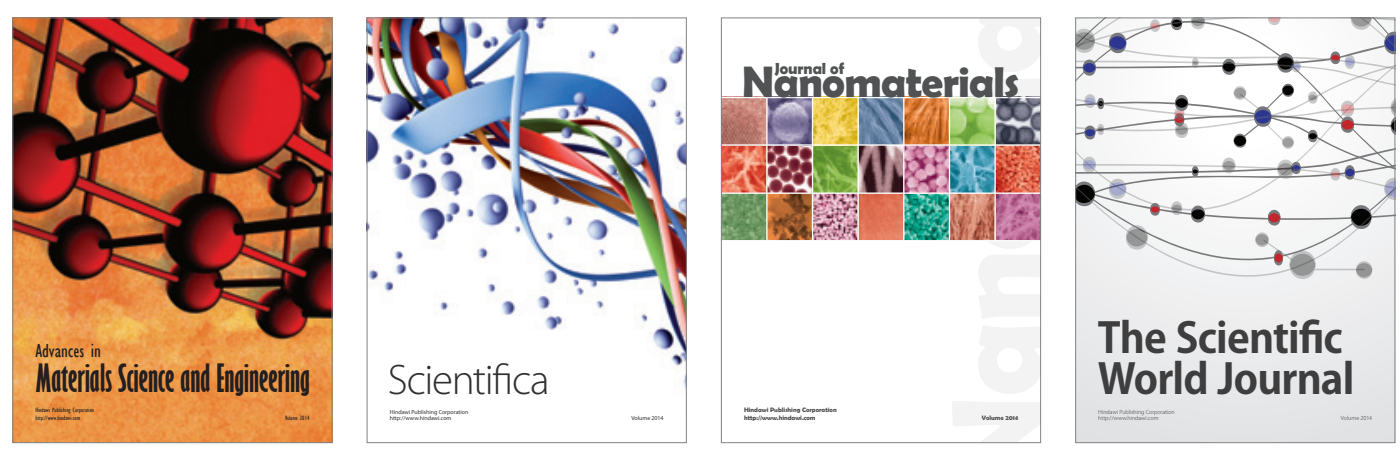

\section{The Scientific World Journal}
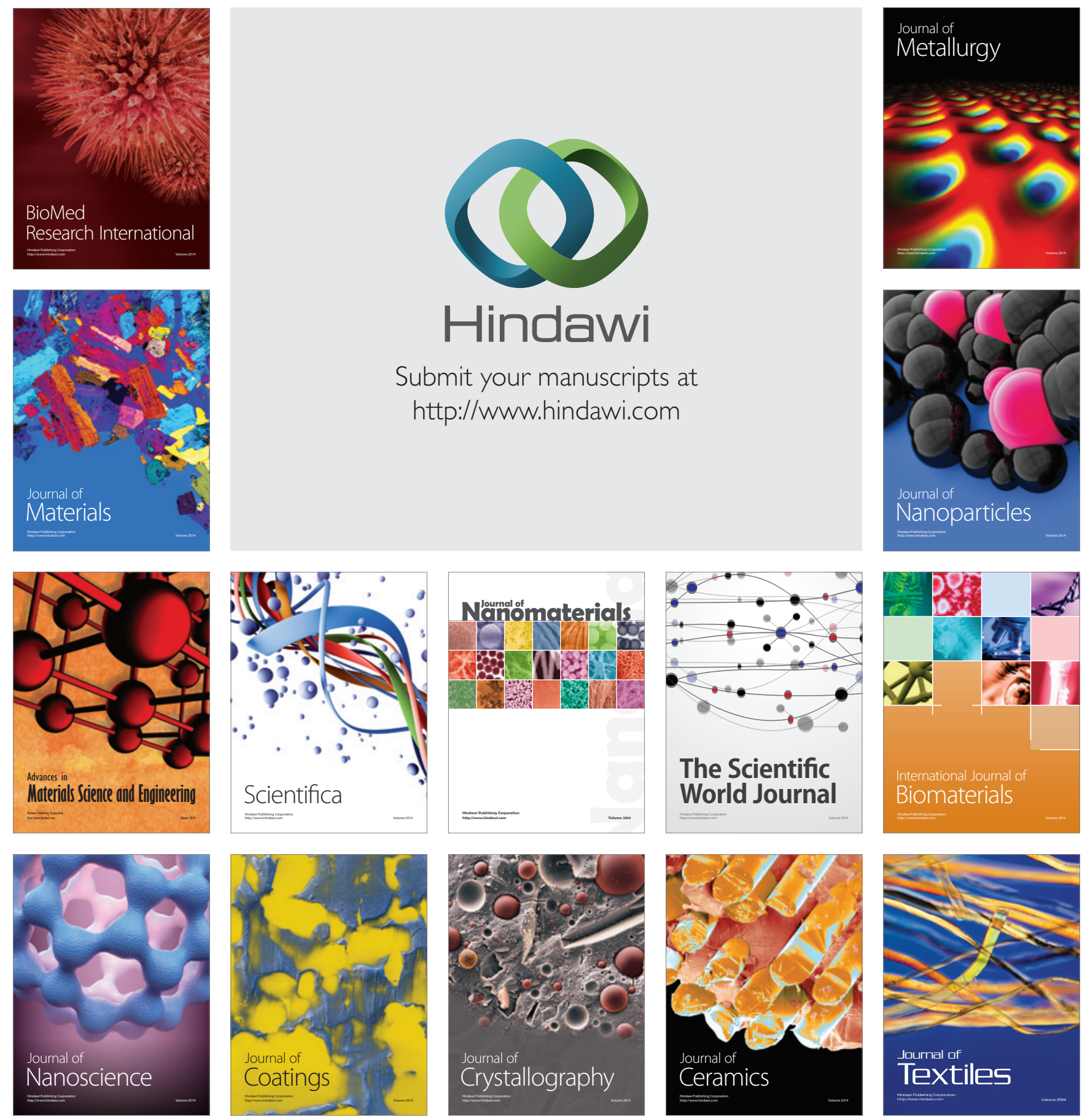